\title{
Reflections on the Construction of Practical Bases for Engineering Education
}

\author{
Wang Yong ${ }^{1, a}$, Liu Qing ${ }^{2, b}$ and Qiu Yongshen ${ }^{1, c}$ \\ ${ }^{1}$ College of Automation, Nanjing University of Posts \& Telecommunications, Nanjing 210023, \\ China; \\ 2 ZhongShan Vocational College, Nanjing 210000, China. \\ anjwy1961@163.com,b526764457@qq.com, ${ }^{c} 576127468 @ q q . c o m$
}

Keywords: Engineering Education, Practice Base, Team Building.

\begin{abstract}
The implementation of "Excellence Plan" is the key step of medium and long-term engineering education reform in China, and an important means to improve the quality of engineering education personnel training. The construction of engineering training base is the guarantee of the " Excellence Plan ". Aiming at the key problem of engineering education in China, the construction of off-campus engineering training center, the construction strategy and content are put forward to ensure the quality of engineering education in China.
\end{abstract}

\section{Introduction}

China's higher engineering education has become the main pillar of economic construction after 100 years of development. However, the expansion of educational scale, the reform of educational system and the change of economic environment in the last decade have exerted a great impact on engineering education, and the hollowing phenomenon of engineering education has become increasingly prominent, which cannot meet the needs of social development. After more than ten years of leap-forward development, higher education has also exposed many problems. Today's decline in teaching quality can make us abandon the dream of catching up with and surpassing the advanced Hong Kong and the international community, give up frivolity and impulse, and give up more serious thinking to enrich our teaching connotation and foundation. The deterioration of the global economic environment in 2012 led to the return of the global real economy. Making 2025 in China is the first ten year plan of action for the Chinese government to implement the strategy of making a strong nation ${ }^{[1]}$.

The national education administration department and the department which produces the enterprise talented person demand also realized the seriousness of the problem, and launched the "Excellence engineer education and training plan". The implementation of the "Plan of Excellence" will fundamentally enrich and reform the mode and content of engineering education. It is a major reform project to implement the "Outline of the National Medium and Long-term Education Reform and Development Plan" deliberated and adopted by the State Council. The past three years are the key 
year for the implementation of the outline of education plan. The implementation of the Excellence Plan is the key to solving the practical problems of "difficult employment" and "labor shortage".

Based on the analysis of the problems and Countermeasures in the practice of Higher Engineering Education in China, this paper discusses the construction concept, ideas and objectives of the practice base of off-campus engineering education.

\section{Problems in engineering education in China}

The development of Higher Engineering Education in China has been tortuous and tortuous due to various factors. In the early stage of reform and opening up, the investment in engineering education is limited, but it can make full use of planned economic resources. The contacts and contacts between engineering education and enterprises and institutions are relatively deep and close. The engineering practice bases of various colleges and universities are also quite adequate. For example, our school has not only an off-campus practice base, but also a fifth Experimental Factory of the Ministry of Posts and Telecommunications, a metalworking operation practice workshop and so on. These resources have made outstanding contributions to our engineering education. ${ }^{[2]}$

With the restructuring of enterprises and the change of the evaluation index of enterprises, the lack of laws or regulations requires enterprises to undertake the social responsibility of participating in the training of engineers. With the transformation of the management system of colleges and universities, colleges and universities have changed from industry subordinate to local, at the same time; they have also weakened their ties with enterprises in the industry. Colleges and universities have closed and sold off their production and practice bases for various reasons. China's higher engineering education has gradually become a castle in the air which is not grounded in the atmosphere. The slogan of cooperation between industry, University and research in training talents has gradually lost its essential connotation. This phenomenon has seriously endangered the innovation and development of China's manufacturing industry. The national implementation of the "excellence Plan" is already recognized the crisis of domestic engineering education. In the Outline of National Medium and Long Term Talent Development Program (2010-2020), the important policy is to establish a strategic alliance of industry, University and research with enterprises as the main body, market as the guide, and various forms under the guidance of the government.

In recent years, the enrollment expansion of colleges and universities has made the resources of software and hardware of Engineering Education in our country tenser, resulting in the decline of education quality. In engineering education, the gap with foreign countries has been widened. At present, the problems existing in the development of Higher Engineering Education in China are mainly manifested in the following aspects:

1) Insufficient investment in education. Due to the particularity of Engineering education, the development of teaching activities and the fulfillment of teaching tasks require a large number of training equipment and practice sites to support, need to invest a large amount of funds to build a training environment to adapt to the pressure brought by the continuous expansion of enrollment and technological progress. The shortage of supply leads to the lack of necessary experimental practice funds and exchange expenses with other countries in engineering education in China, which has a great impact on the development of engineering education.

2) Lack of engineering training and loose connection with enterprises. The combination of production, teaching and research has been fully practiced both at home and abroad, which proves to be an excellent training mode of modern engineering education and an important part of the engineering education system. Influenced by many factors, engineering education in our country is gradually breaking away from the contact with enterprises. The cultivation of students' engineering quality is basically completed in a closed campus. The connection with social and technological 
development is not close enough. The phenomenon of emphasizing theory over practice is becoming more and more obvious. The cultivation goal has already met the needs of talents in industrial enterprises. The opportunity for students to take part in enterprise inspection and training is not as rich as in the 80s of last century. Practice content is gradually decreasing, virtual and simulation teaching methods and content are increasing, students lack enough engineering practice training, ability to solve practical engineering problems and poor hands-on ability.

3) The training mode is single. At present, constrained by the evaluation mechanism, our country's colleges and universities have a serious tendency of simplification, lack of individuality and characteristics, and a serious tendency of identity. The reform of teaching content and teaching methods is lagging behind foreign institutions and is seriously out of touch with social development. Although many colleges and universities have made some explorations and reforms in the curriculum system, teaching content and methods, but restricted by the evaluation mechanism, funds and other factors, the teaching content is still based on professional knowledge education, engineering practice ability training reform is lacking, the development is slow.

Schools can no longer meet the requirements of enterprises for the quality of talents by training talents in accordance with the unified and disconnected mode with enterprises.

4) Lack of qualified teachers. When introducing teachers, schools place too much emphasis on academic qualifications and academic level, such as the number of PhD graduates from 985 or 211 universities, the number of SCI or EI papers published, often do not check whether they have qualified engineering education background. Research topics tend to basic and theoretical research, assessment indicators are based on the number of papers and projects, while ignoring the content and quality. This has great limitations to the development of engineering education at this stage.

Due to the limitation of funds and policies, it is difficult for school teachers to receive engineering training from enterprises and to recruit outstanding engineering and technical personnel to become the instructors of engineering education. Due to various reasons, outstanding engineering and technical personnel in the school are expected to develop in companies and foreign enterprises, engineering education brain drain is serious. The shortage of teachers and engineering literacy hinder the cultivation of students' engineering manufacturing and practical ability. Due to the lack of links between teachers and enterprises, the project vision is constrained, so that the ability to innovate is affected, leading to research results and inventions far less than foreign engineering education.

\section{Strengthening the construction of Engineering Education}

In order to explore a new train of thought for training outstanding engineers under the new situation, and in view of the problems existing in the execution process of Engineering Education in our country at this stage, we have combined with enterprises to give full play to the respective advantages of schools and enterprises, and carried out the construction of the practice center of off-campus engineering education.

On the premise that neither the government nor the universities can meet the needs of the universities for the development of Engineering talents, attracting enterprises to invest and participate in the construction of engineering education resources has become an important way to complete and develop the "Excellence Plan".

In the process of constructing the practice center of off-campus engineering education, we should learn from the successful experience of foreign higher engineering education, learn from the powerful country of higher engineering education, and combine with the actual situation of the development of Higher Engineering Education in our country.

1) In view of the shortage of funds and resources for the project education of the "Plan of Excellence", the corresponding solutions are put forward: to cooperate with enterprises to build a 
joint laboratory, to improve the engineering education environment by utilizing enterprise resources; to send teachers to enterprises for further study, to recruit outstanding enterprise engineers as outside-school tutors, and to integrate and optimize existing teaching resources. In order to ensure the effective implementation of the Excellence Plan, more than ten well-known enterprises in our institute have signed the construction of practice bases and the agreement of production, teaching and research practice, which stipulates the learning tasks and contents. More than 100 technical and managerial experts were employed as part-time instructors to clarify the tasks and responsibilities of the work. Establish strategic alliance with enterprises, cooperate in multi-level and multi-faceted, and complement each other in resources such as engineering teaching and project development.

2) Establishing the system of training engineers both inside and outside school and innovating the mechanism of training talents jointly by colleges and universities and industrial and mining enterprises require the close participation and cooperation of industry. Enterprises participate in the training of engineers, and teach a certain proportion of practical courses by enterprise engineers or practice in enterprises. This requires not only the protection of national laws and regulations, but also the sense of social responsibility and strategic vision of the business community. The off-campus training system for engineers is a new kind of cooperative education system. It should be supervised and managed jointly by the administrative department of education and the competent department of industry. The trade associations should coordinate and provide services in a unified way. The schools should pay the costs and expenses of the enterprises for the engineering practice, or the State Taxation and policies should be directed to the enterprises undertaking the engineering education. The industry is inclined.

3) To a large extent, the effectiveness and quality of engineering education depend on the guidance of teachers. The construction and training of teachers in engineering education has become an important factor determining the quality assurance of education. We should abandon the current standards and policies of evaluating engineering education by the number of articles, especially the number of articles. We should attract and encourage teachers with correct values and reasonable policy orientation so as to actively participate in the research and practice of education reform.

In policy, teachers should be encouraged to obtain various kinds of professional qualifications or to take part-time jobs in enterprises, so as to cultivate and train full-time teachers' practical and engineering abilities, and improve the training system for engineers.

4) The establishment and construction of teaching contents in practical courses. In accordance with the needs of engineering education, the curriculum system should be reformed, the training objectives of talents with "engineering ability" as the core should be strengthened, the engineering training centers inside and outside schools should be established, and the engineering practice hours should be increased.

Student-centered, combined with the production and management characteristics of different enterprises, designed a personalized student participation project research plan. Let the student participate in the project research work of the teacher in the enterprise, increase the knowledge and ability in the practice process. We should strengthen the organization and management of the plan; formulate effective policies and incentive mechanisms to attract the participation of teachers and students.

5) The combination of engineering quality and engineering ability training with professional certification. At present, the registration system of primary and secondary structural engineers, which is in line with international standards, is already in operation in China, and the system of other professional registered engineers is also in the process of starting. 


\section{Summary}

The characteristics of the training program for outstanding engineers are as follows: 1 . Industrial enterprises are deeply involved in the process of personnel training and shaping; 2. Colleges and universities cultivate technical personnel according to common standards and industry standards; 3 . Emphasis is laid on cultivating students' innovative ability, engineering quality and practical ability. Promoted by the plan of excellence, our school has given full play to the advantages of regional industry, education and research, relying on the joint operation of industry, education and research, and has established more than ten out-of-school practical teaching bases in cooperation with enterprises and institutions, forming a reasonable layout, relatively stable, sufficient number of engineering education and training sites with a wide geographical distribution.

\section{Acknowledgements}

Project Supported by Nanjing University of Posts and Telecommunications foundation project (2018XSG09)

\section{References}

[1] Zhang Mengfang, New requirements and Countermeasures for higher engineering education made by "made in China 2025", Journal of Huanggang Normal University, 2018, No.4:49-54.

[2] Liu Mengyuan, Problems and improvement strategies of Higher Engineering Education in China, Reform \& Openning, 2018, No.15:131-146.

[3] Ren Jie, Research on management system of higher vocational education practice base, The Science Education Article Collects, 2017, No.5:96-142. 